\title{
An atypical case of eosinophil-Rich Sweet's syndrome
}

\section{Yosra Soua1, Mohamed Ben Rjeb', Adnène Moussa ${ }^{2}$, Syrine Dadaa ${ }^{3}$, Ines Laouel'1, Hichem Belhadjali', Monia Youssef', Jameleddine Zili'1}

${ }^{1}$ Department of Dermatology, Fattouma Bourguiba Hospital, Monastir, Tunisia, ${ }^{2}$ Department of Anatomopathology, Fattouma Bourguiba Hospital, Monastir, Tunisia, ${ }^{3}$ Department of Internal Medicine, Fattouma Bourguiba Hospital, Monastir, Tunisia.

Corresponding author: Dr. Soua Yosra, E-mail: soua-yosra@hotmail.fr

\begin{abstract}
Sweet's syndrome is an inflammatory disease that occurs mainly in young adults. Its clinical and histological aspects are usually characteristic. Its diagnostic criteria were proposed by von den Driesch. Two major and at least two minor criteria are required to establish the diagnosis. Sweet's syndrome is classically associated with neutrophilic infiltrate. A few cases of Sweet's syndrome with dense eosinophil infiltrate have been described. Here, we report a new case of eosinophil-rich Sweet's syndrome in a young woman without underlying pathology.
\end{abstract}

Key words: Sweet's syndrome; Eosinophils; Neutrophils

\section{INTRODUCTION}

Sweet's syndrome is an inflammatory disease that occurs mainly in young adults. Its clinical and histological aspects are usually characteristic. Sweet's syndrome is classically associated with neutrophilic infiltrate [1]. A few cases of Sweet's syndrome with dense eosinophil infiltrate have been described. Here, we report a new case of eosinophil-rich Sweet's syndrome in a young woman without underlying pathology.

\section{CASE REPORT}

A previously healthy 30-year-old woman presented with an abrupt onset of inflammatory erythematous plaques associated with polyarthralgia and fever evolving for the past week. No new drug intake or insect bites were noted. A physical examination revealed inflammatory and infiltrated plaques and nodules on the upper limbs. On the lower limbs, large pseudo-urticarial inflammatory plaques with centrifugal extension and purplish borders were noted (Fig. 1). The rest of the examination did not reveal further abnormalities. A biological assessment showed an accelerated sedimentation rate, CRP at $45 \mathrm{mg} / \mathrm{L}$, and hyperleukocytosis at 11,000 cells $/ \mathrm{mm}^{3}$ with a predominance of polynuclear neutrophilic leukocytes. Cutaneous biopsies from the forearm and thigh showed an edematous dermis with perivascular inflammatory infiltrate rich in neutrophils (Fig. 2) and eosinophilic polynuclear cells, with leukocytoclasia and collagen necrobiosis (Fig. 3). A thoracoabdominopelvic scan was without abnormalities, and an immunological assessment was negative. The patient was treated with corticosteroid therapy at a dose of $1 \mathrm{mg} / \mathrm{kg} /$ day with a marked improvement.

\section{DISCUSSION}

Sweet's syndrome (SS) is an inflammatory disease that occurs mainly in young adults with a predominance in females. Its diagnostic criteria were proposed by von den Driesch [2]. The presence of two major and at least two minor criteria establishes the diagnosis of SS. The major criteria are (1) an abrupt onset of painful erythematous plaques or nodules and (2) a predominantly neutrophilic infiltration of the dermis without leukocytoclastic vasculitis. The minor criteria are (1) association with a respiratory or gastrointestinal tract infection, vaccination, inflammatory disease, malignancy, or pregnancy, (2) fever, (3) abnormal

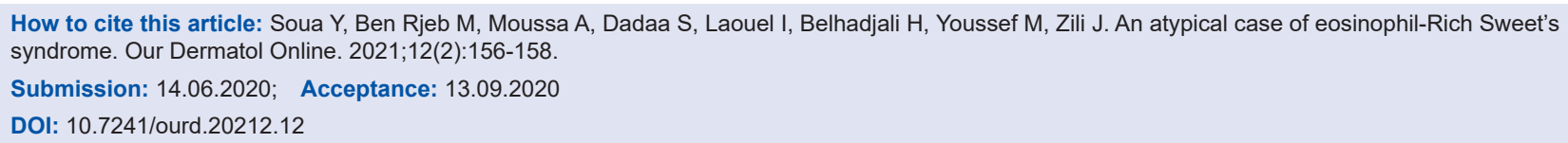




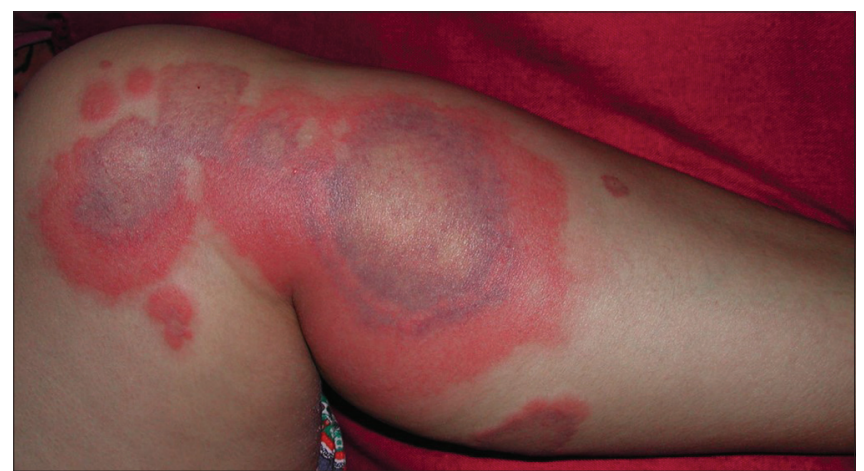

Figure 1: A large plaque with a centrifugal extension, purplish center, and inflammatory borders.

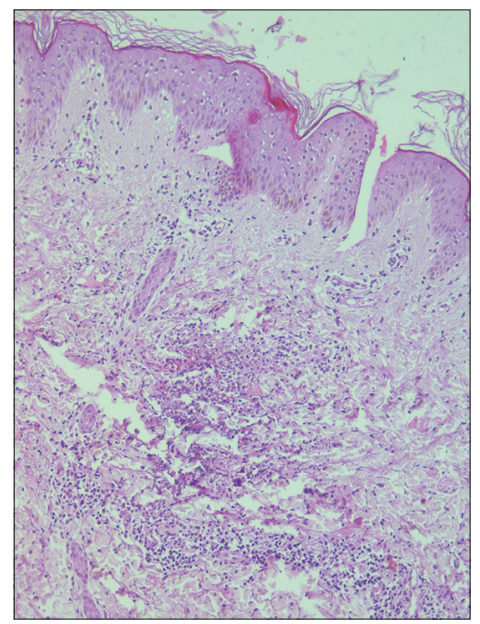

Figure 2: An edematous dermis with perivascular inflammatory infiltrate rich in neutrophils and eosinophilic polynuclear cells (H\&E, $\times 40)$.

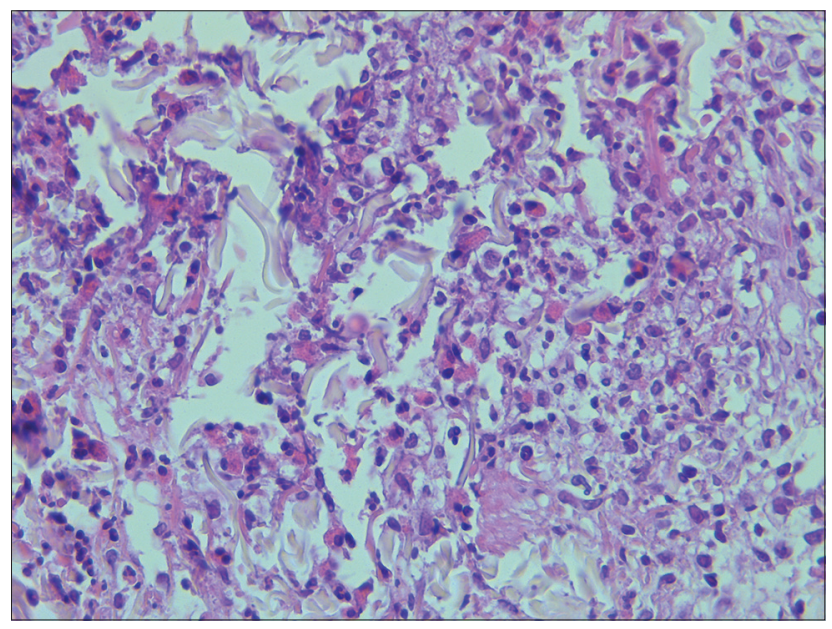

Figure 3: Dermal inflammatory infiltrate rich in neutrophils and eosinophilic polynuclear cells with collagen necrobiosis (H\&E, $\times 400)$.

laboratory values-erythrocyte sedimentation rate (ESR) at $20 \mathrm{~mm} / \mathrm{h}$, a raised level of C-reactive protein, leukocytosis at 8000 cells $/ \mathrm{mL}, 70 \%$ neutrophils in peripheral blood ( 3 out of 4 abnormal laboratory values required for the diagnosis) — and (4) excellent response to treatment with systemic corticosteroids or potassium iodide. Our patient fulfilled the two major criteria and two minor criteria of SS. In our patient, the minor criteria were blood neutrophilia and excellent response to systemic corticosteroids [1]. The diagnosis of Sweet's syndrome was upheld, but it was particular by its histology. Sweet's syndrome is classically associated with neutrophilic infiltrate. Additional features of leukocytoclastic vasculitis may be present [1]. Unusual histopathologic variants of Sweet's syndrome, including histiocytoid Sweet's syndrome, have been reported [3]. The presence of eosinophils in the neutrophilic infiltrates of acute febrile neutrophilic dermatosis has also been reported in the literature. In a histopathological review of 73 cases, eosinophilic infiltration was present in up to $40 \%$ of the lesions and associated, in some cases, with eosinophilia in peripheral blood [4]. The pathogenesis of eosinophil infiltrate in this syndrome has not been well understood. Cases with dense eosinophilic infiltrates are much rarer. To the best of our knowledge, four cases of eosinophils-rich Sweet's syndrome have been reported [5]. Among these, a patient with a B-cell lymphoma developed Wells' syndrome, following eosinophil-rich Sweet's syndrome [6]. Another patient, with a subsequent appearance of Wells' syndrome, Sweet's syndrome, and leukocytoclastic vasculitis, developed a ganglial lymphoma for several months [7]. Other underlying processes of SS may include inflammatory bowel disease, infection, pregnancy, or medication. Neoplastic diseases are associated with approximately $20 \%$ of cases [8]. Clinical manifestations can precede the diagnosis of a neoplasm in patients. Although etiological investigations were negative in our patient, monitoring should be continued to detect a later association of pathology.

\section{CONCLUSION}

We report here the case of a particular form of Sweet's syndrome rich in eosinophils.

\section{Consent}

The examination of the patient was conducted according to the principles of the Declaration of Helsinki.

The authors certify that they have obtained all appropriate patient consent forms, in which the patients have given consent for images and other clinical information to be included in the journal. The patients understand that their names and initials will not be published and due effort will be made to conceal their identity, but that anonymity cannot be guaranteed. 


\section{REFERENCES}

1. Villarreal-Villarreal CD, Ocampo-Candiani J, Villarreal-Martínez A. Sweet Syndrome: A Review and Update. Actas Dermosifiliogr. 2016;107:369-78.

2. Von den Driesch P. Sweet's syndrome (acute febrile neutrophilic dermatosis). J Am Acad Dermatol. 1994;31:535-56; quiz 557-60.

3. Wark KJ, Crawshaw H. Histiocytoid Sweet syndrome. Med J Aust. 2019;211:400-400.

4. Rochael MC, Pantaleão L, Vilar EAG, Zacaron LH, Spada EQ, Xavier MHSB, et al. Sweet's syndrome: study of 73 cases, emphasizing histopathological findings. An Bras Dermatol. 2011;86:702-7.

5. Masuda T, Abe Y, Arata J, Nagao Y. Acute febrile neutrophilic dermatosis (Sweet's syndrome) associated with extreme infiltration of eosinophils. J Dermatol. 1994;21:341-6.
6. Soon CW, Kirsch IR, Connolly AJ, Kwong BY, Kim J. EosinophilRich Acute Febrile Neutrophilic Dermatosis in a Patient With Enteropathy-Associated T-cell Lymphoma, Type 1. Am J Dermatopathol. 2016;38:704-8.

7. Consigny S, Courville P, Young P, Richard C, Gauthier V, Maillard V, et al. Histological and clinical forms of the eosinophilic cellulitis. Ann Dermatol Venereol. 2001;128:213-6.

8. Paydas S. Sweet's syndrome: a revisit for hematologists and oncologists. Crit Rev Oncol Hematol. 2013;86:85-95.

Copyright by Soua Yosra, et al. This is an open-access article distributed under the terms of the Creative Commons Attribution License, which permits unrestricted use, distribution, and reproduction in any medium, provided the original author and source are credited.

Source of Support: Nil, Conflict of Interest: None declared. 